\section{Original Article}

Journal of Epilepsy Research pISSN 2233-6249 / eISSN 2233-625

Received March 18, 2017

Accepted May 19, 2017

Corresponding author: Gašper Zupan

University of Ljubljana, Faculty of

Medicine, Vrazov trg 2, 1000 Ljubljana,

Slovenia.

Tel. +386-1-543-70-69

Fax. +386-1-543-70-21

E-mail; gasper.zupan@mf.uni-lj.si

\title{
Knowledge and Awareness of Epilepsy Surgery among Medical Students
}

\author{
Gašper Zupan, ${ }^{1}$ Bogdan Lorber ${ }^{2}$ \\ ${ }^{1}$ University of Ljubljana, Faculty of Medicine, Vrazov trg 2, Ljubljana, Slovenia; ${ }^{2}$ Department of Neurology, \\ University Medical Centre Ljubljana, Zaloška 2, Ljubljana, Slovenia
}

Background and Purpose: Surgery is an alternative treatment of drug-resistant epilepsy. Positive attitude of medical personnel towards epilepsy surgery is essential. This study assessed general knowledge of and attitude towards epilepsy surgery among medical students. The aim of this study was to assess general knowledge of and attitude towards epilepsy surgery among medical students.

Methods: Questionnaire was distributed to medical students. Questionnaire consisted of two questions of general knowledge of drug-resistant epilepsy, questions of students' attitude towards epilepsy surgery and questions of referral of patients. The Chi-square test was utilized.

Results: The terms "drug-resistant epilepsy" and "mesial temporal sclerosis" were known in 72.3 and 14.2 percent, respectively. Awareness and support of epilepsy surgery were recorded in 74.5 and 48.9 percent, respectively. A drug resistant patient would have been referred to a qualified centre in 19.4 percent. General knowledge and awareness of epilepsy surgery were better in higher levels of study $(p<0.001)$.

Conclusions: Medical students have a positive attitude towards epilepsy surgery. Students are aware of drug resistance in epilepsy. Knowledge and awareness are better among students in higher levels, after neurology is introduced to the curriculum. We conclude that highlighting the importance of epilepsy surgery should be continued. Moreover, additional educational effort should be invested in expressing the importance of efficient referral of a patient to a qualified centre. (2017;7:50-53)

Key words: Epilepsy, Students, Neurosurgery

\section{Introduction}

Epilepsy is one of the most common chronic neurological diseases with the prevalence of about one percent. ${ }^{1}$ The failure rate of treatment with antiepileptic drugs (AED) is 20-30 percent. ${ }^{2}$ Drug-resistant epilepsy is defined by the International League Against Epilepsy (ILAE) as a failure of adequate trials of two tolerated and appropriately chosen and used AED schedules to achieve sustained seizure freedom. ${ }^{3}$ Most of the patients with developed drug resistance never become free of seizures with medical treatment alone. ${ }^{4}$ Benbadis and coworkers report that it takes on average 18 years before patients are referred to an epilepsy centre to consider non-pharmacological treatment. ${ }^{5}$ Analysis of the trends of epilepsy surgery in the USA demonstrated that surgical procedures in this field are heavily underutilized. ${ }^{6}$ Therefore, positive attitude of medical personnel towards alternative treatment options is important to patients with drug-resistant epilepsy. The aim of this study was to assess general knowledge of and attitude towards epilepsy surgery among medical students.

\section{Methods}

Online poll was distributed to all available e-mail addresses of medical students of Faculty of Medicine, University of Ljubljana, Slovenia. Syllabus of Faculty of Medicine Ljubljana lasts six years. In essence, students are introduced to basic science in the first half and they start their clinical rotations in the second half of the study. Neurology is a part of the mandatory curriculum in the fourth year. However, several extra-curriculum neurological or neurology-related activities are available and encouraged by the Faculty of Medicine.

Questionnaire was short with the first part consisting of two questions of general knowledge of drug resistant epilepsy, followed by questions of students' attitude towards epilepsy surgery and referral of patients, ending it with demographic questions. The survey was 
opened 72 hours. Full questionnaire is available in Supplementary Table 1. All incomplete surveys were excluded from the study.

General statistics of the results were produced. Students were divided according to their level of study. The Chi-square test was used for statistical analysis of differences between variables. A $p$-value of $<0.05$ was considered significant. Statistical analysis was carried out using PSPP ver. 0.9.0 (GNU; Free Software Foundation, Boston, MA, USA).

\section{Results}

Most of the responses came in within the first 24 hours. In 72 hours, 325 completed questionnaires were received. Detailed demographic data is shown in Table 1. Sex, level of study and age can be observed (Table 1).

Most of the students reported that they were familiar with the term "drug-resistant epilepsy" (72.3\%), however, their knowledge of the term "mesial temporal sclerosis" was poor in $85.8 \%$ of cases. Students answered that they were aware of possible surgical treatment of some cases of epilepsy (74.5\%) and that they generally would have supported an operation (48.9\%). Only 2 students answered that they would not have encouraged a patient to undergo an operation. As the most common referral option for a patient with drug-resistant epilepsy, students chose a general neurologist

Table 1. Demographics

\begin{tabular}{lc}
\hline Characteristic & Values \\
\hline Sex & \\
Male & $95(29.2)$ \\
Female & $230(70.8)$ \\
$\sum$ & $325(100)$ \\
Level of study & \\
$1^{\text {st }}$ & $33(10.2)$ \\
$2^{\text {nd }}$ & $42(12.9)$ \\
$3^{\text {rd }}$ & $52(16.0)$ \\
$4^{\text {th }}$ & $44(13.6)$ \\
$5^{\text {th }}$ & $53(16.3)$ \\
$6^{\text {th }}$ & $43(13.2)$ \\
Others* & $58(17.8)$ \\
$\sum$ & $325(100)$ \\
Age & \\
$0-20$ & $53(16.3)$ \\
$21-24$ & $182(56.0)$ \\
$25-30$ & $88(27.1)$ \\
$31-40$ & $2(0.6)$ \\
$40-$ & $0(0.0)$ \\
$\sum$ & $325(100)$ \\
\hline
\end{tabular}

Values are presented as number (\%).

*Finished the curriculum but not graduated yet.
(76.6\%). However, $19.4 \%$ would have referred a patient to a specialized Centre for Adult Epilepsy. Full responses are listed in Table 2.

When knowledge and referral patterns were compared to the level of study, general knowledge of epilepsy surgery was better in higher levels of study $(p<0.001)$. Moreover, awareness of surgical treatment of epilepsy was also better in the last years of study ( $p<$ 0.001). However, the association of choice of referral and the level of study was not statistically significant $(p=0.66)$. Detailed analysis is shown in Table 3.

\section{Discussion}

Results of this study are encouraging and generally show a positive attitude of medical students in our sample group towards epilepsy surgery. As shown in Table 2, most of the participants answered

Table 2. Collected responses of the students

\begin{tabular}{|c|c|}
\hline Questions & Values \\
\hline \multicolumn{2}{|l|}{ Do you know the term "drug-resistant epilepsy"? } \\
\hline Yes & $235(72.3)$ \\
\hline No & $90(27.7)$ \\
\hline$\sum$ & $325(100)$ \\
\hline \multicolumn{2}{|l|}{$\begin{array}{l}\text { Do you know the term "mesial temporal } \\
\text { sclerosis"? }\end{array}$} \\
\hline Yes & $46(14.2)$ \\
\hline No & $279(85.8)$ \\
\hline$\sum$ & $325(100)$ \\
\hline \multicolumn{2}{|l|}{$\begin{array}{l}\text { What would you do with an adult patient who } \\
\text { was introduced to two different regimes of } \\
\text { appropriate antiepileptic drugs with no side } \\
\text { effects and without improvement in seizure } \\
\text { control? }\end{array}$} \\
\hline Treat him/her myself & $0(0.0)$ \\
\hline Refer to a neurologist & $249(76.6)$ \\
\hline Refer to a neurosurgeon & $12(3.7)$ \\
\hline Refer to the Centre for adult epilepsy & $63(19.4)$ \\
\hline Refer to a radiologist & $1(0.3)$ \\
\hline$\Sigma$ & $325(100)$ \\
\hline \multicolumn{2}{|l|}{$\begin{array}{l}\text { Have you heard that in some cases epilepsy can } \\
\text { also be treated surgically? }\end{array}$} \\
\hline Yes & $242(74.5)$ \\
\hline No & $83(25.5)$ \\
\hline$\sum$ & $325(100)$ \\
\hline \multicolumn{2}{|l|}{$\begin{array}{l}\text { If one of your patients would have drug-resistant } \\
\text { epilepsy and a senior epileptologist would } \\
\text { recommend referring him or her to epilepsy } \\
\text { surgery, what would you do? }\end{array}$} \\
\hline I would support an operation & $159(48.9)$ \\
\hline $\begin{array}{l}\text { I do not have enough knowledge, therefore I } \\
\text { would try to gather more information }\end{array}$ & $164(50.5)$ \\
\hline I would not support an operation & $2(0.6)$ \\
\hline$\sum$ & $325(100)$ \\
\hline
\end{tabular}


that they were aware of drug resistance among patients with epilepsy $(72.3 \%)$ and that surgical treatment for some types of epilepsy was available (74.5\%). However, students reported lack of knowledge of the term "mesial temporal sclerosis" in 85.8 percent. Even though not all patients with mesial temporal sclerosis (MTS) have epilepsy or drug-resistant epilepsy, ${ }^{7}$ MTS is one of the most common pathologies encountered among patients suitable for epilepsy surgery. ${ }^{8}$ This outcome was expected since regular medical education does not provide all the details of this specific field to the students. However, detailed knowledge was not essential for a positive attitude towards epilepsy surgery, since $48.9 \%$ of students expressed support for a surgical procedure. Moreover, just a few students would have disagreed with an eventual operation ( $0.6 \%)$. However, $50.5 \%$ of students were indecisive and they admitted their lack of knowledge of this topic. The authors believe that attention should be focused on epilepsy surgery role and benefits to patients with drug-resistant epilepsy.

If students were put in the position of a general physician treating a patient with refractory epilepsy, most of them would have referred a patient to a regular neurologist (76.6\%). Depending on organization of health services in a region or a country, a patient could visit a general neurologist that is not an epilepsy expert. The importance of advocating that a patient with drug-resistant epilepsy must be referred to an epilepsy centre may be seen in American studies of re- view of trends of epilepsy procedures between 1990 and 2008. They found an increase in patient admittance, especially in small centres, however an increase in operations was not observed. Several explanations were offered: higher number of unsuitable candidates for surgery, novel AEDs and the inexperience of small hospitals. Therefore, more challenging lobectomies were not performed as often. ${ }^{6}$ A similar situation was observed in the United Kingdom where a decrease in procedures was noted with the exception of vagus nerve stimulation implantations. ${ }^{9}$ Jehi and coworkers reported a negative trend of medial temporal lobe epilepsy-related surgery. That might be due to increase of extratemporal resections, ${ }^{10}$ however the general recommendation in the professional community still advocates treating refractory epilepsy in highly specialized centres. Hakimi and coworkers proposed that a lack of communication between referring neurologist and an epileptologist in a specialized centre negatively impacted referring physician's views on epilepsy surgery. ${ }^{11}$ In our study only $19.4 \%$ of students would refer a patient to the Centre for Adult Epilepsy, which is the only highly specialized centre in Slovenia. Since we tested the population of medical students, it is impossible to conclude that general physicians themselves are not informed enough and therefore they may be the cause of wrong referrals and delaying the patients. Nonetheless, authors recommend more attention is already paid to this issue in the process of undergraduate education.

Table 3. Comparison between level of study and the answers

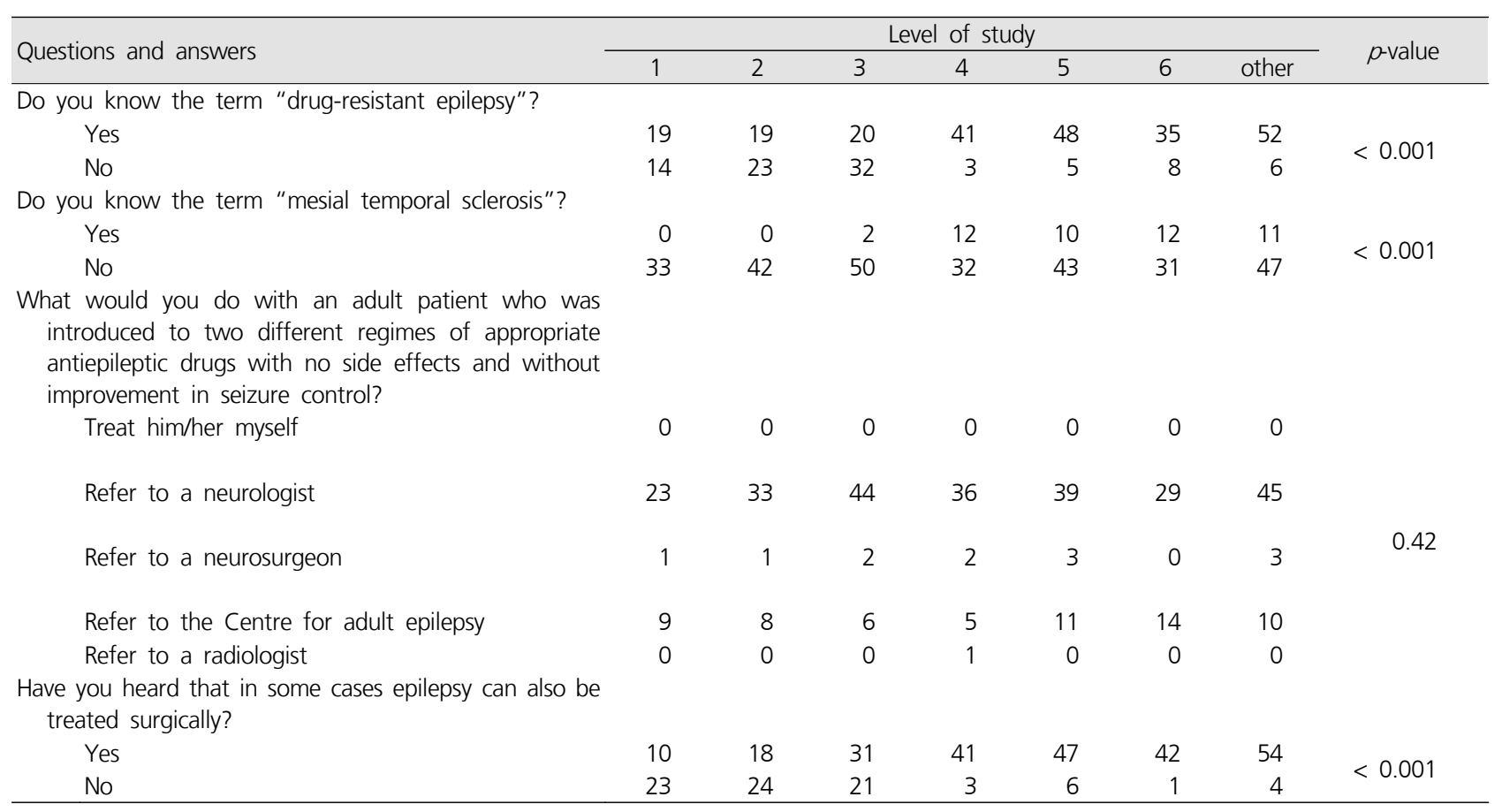


Higher level of study affects knowledge of epilepsy surgery ( $p<$ 0.001 ). That can be explained by the fact that students are introduced to neurology in the fourth year of the curriculum at our faculty. However, the authors want to emphasize that better knowledge in the last years of study might also be due to involving students in extra-curricular activity, such as accompanying patients to the surgical treatment at the University Hospital Erlangen, Germany, working in long-term epilepsy monitoring units during nights and weekends in our centre and including students in clinical research work. We believe that practical experience is worth more than theoretical knowledge, therefore we would like to encourage other universities to offer opportunities to students to gain insight into patients' problems as well as diagnostic and treatment options.

To our best knowledge, a study of knowledge of epilepsy surgery among medical students has not yet been performed. Recently, a study of knowledge of epilepsy among medical students was performed in Turkey. ${ }^{12}$ Authors did not focus on epilepsy surgery per se, however $25.2 \%$ of students chose brain surgery as a possible treatment of epilepsy. In another study among Swedish neurologists, ${ }^{13}$ results showed general positive attitude in favor of epilepsy surgery, with extremely high opinion about the cost efficiency of the treatment $(92 \%)$. Interestingly, most of the neurologists tried out three or more anti-epileptic drugs before considering surgery (82.1\%), which may be considered too long and shows a hesitation despite a general preference for epilepsy surgery. Italian ${ }^{14}$ researchers found a better attitude towards surgery in a group of consultants in the field of neurology than among other neurologists, pointing out the lack of experience and relevant data in the latter group. In Canada, nationwide research was performed ${ }^{15}$ and almost half of neurologists incorrectly defined drug-resistant epilepsy. The above mentioned studies involving medical doctors are not directly translatable to our research setting. However, they might offer some reasons responsible for underutilization of epilepsy surgery.

In conclusion, the study shows that general awareness of epilepsy surgery among students of Faculty of Medicine, University of Ljubljana is very good. This study found inadequate referral decisions of medical student and indecisiveness of students due to lack of knowledge of epilepsy surgery. We welcome the activity of the ILAE and other societies for their worldwide contribution. Moreover, we also encourage all institutions involved in medical education to highlight the importance of epilepsy surgery in improving seizures and quality of life. ${ }^{4}$

\section{Conflict of Interest}

Authors of this article declare that we have no conflicts of interest.

\section{References}

1. Engel Jr. J, Pedley TA. Epilepsy: a comprehensive textbook (volume one), 1st ed. Philadelphia: Lippincott-Raven Publishers, 1997.

2. Sanders JW. Some aspects of prognosis in the epilepsies: a review. Epilepsia 1993;34:1007-16.

3. Kwan P, Arzimanoglou A, Berg AT, et al. Definition of drug resistant epilepsy: consensus proposal by the ad hoc Task Force of the ILAE Commission on Therapeutic Strategies. Epilepsia 2010;51:1069-77.

4. Wiebe $S$, Jette N. Epilepsy surgery utilization: who, when, where, and why? Curr Opin Neurol 2012;25:187-93.

5. Benbadis SR, Heriaud L, Tatum WO, Vale FL. Epilepsy surgery, delays and referral patterns-are all your epilepsy patients controlled? Seizure 2013;12:167-70.

6. Englot DJ, Ouyang D, Garcia PA, Barbaro NM, Chang EF. Epilepsy surgery trends in the United States, 1990-2000. Neurology 2012;78:1200-6

7. Wieser HG; ILAE Commission on Neurosurgery of Epilepsy. Mesial temporal lobe epilepsy with hippocampal sclerosis. Epilepsia 2004:45:695-714.

8. de Tisi J, Bell GS, Peacock JL, et al. The long-term outcome of adult epilepsy surgery, patterns of seizure remission, and relapse: a cohort study. Lancet 2011;378:1388-95.

9. Neligan A, Haliasos N, Pettorini B, Harkness WF, Solomon JK. A survey of adult and pediatric epilepsy surgery in the United Kingdom. Epilepsia 2013;54(5):e62-5.

10. Jehi L, Friedman D, Carlson C, et al. The evolution of epilepsy surgery between 1991 and 2011 in nine major epilepsy centers across the United States, Germany, and Australia. Epilepsia 2015;56:1526-33.

11. Hakimi AS, Spanaki MV, Schuh LA, Smith BJ, Schultz L. A survey of neurologists' views on epilepsy surgery and medically refractory epilepsy. Epilepsy Behav 2008;13:96-101.

12. Kartal A. Knowledge of, perceptions of, attitudes and practices regarding epilepsy among medical students in Turkey. Epilepsy Behav 2016:58:115-8

13. Kumlien E, Mattsson P. Attitudes towards epilepsy surgery: a nationwide survey among Swedish neurologists. Seizure 2010;19:253-5.

14. Erba G, Moja L, Beghi E, Messina P, Pupillo E. Barriers toward epilepsy surgery. A survey among practicing neurologists. Epilepsia 2012; $53: 35-43$.

15. Roberts Jl, Hrazdil C, Wiebe S, et al. Neurologists' knowledge of and attitudes toward epilepsy surgery: a national survey. Neurology 2015;84:159-66. 